\title{
Antsiolitiko eta hipnotiko sedagarrien kontsumoa: generoaren araberako analisia nazioartean eta Euskal Autonomia Erkidegoan
}

\section{Analysis of gender-based consumption of anxiolytics andsedative hypnotics in thelnternational and in the Basque Country Autonomous Communities}

\author{
Ane del Palacio Totoricagüena ${ }^{1}$, Joseba Pineda Ortiz $^{2}$ eta Aitziber Mendiguren Ordorica ${ }^{2}$ \\ ${ }^{1}$ Galdakaoko ESI, Etxebarriko Osasun Zentroa, Familia eta Komunitate Arretako BAME \\ ${ }^{2}$ UPV/EHU, Farmakologia Saila, Medikuntza eta Eritzaintza Fakultatea
}

Ane.delPalacioTotoricaguena@osakidetza.eus

\section{Laburpena}

Antsietatea ezbeharrei aurre egiteko erreakzioa da,baina atalase bat gainditzen duenean patologikoa izan daiteke. Loezinak, aldiz, loak hartzeko edo hura mantentzeko zailtasunari zein goizegi esnatzeari egiten dio erreferentzia. $\mathrm{Bi}$ nahasmendu hauen tratamendurako psikofarmakoak diren bentzodiazepinak (BDZ) eta hipnotikoak erabiltzen dira batik bat. Espainian psikofarmakoen kontsumoa handia da.

Ikerlan honen helburuak honakoak izan ziren: 1) Nazioartean antsiolitikoen eta hipnotikoen kontsumoaren generoaren araberako analisia egitea. 2) 2006-2018bitartean Euskal Autonomia Erkidegoan(EAE) antsiolitiko eta hipnotikoen generoaren araberako kontsumoaren landa-ikerketa egitea. Ikerlana gauzatzeko bilaketa bibliografiko sistematizatua egin zen bost datu-basetan eta EAEkoantsiolitiko eta hipnotikoen kontsumoa analizatu zen.

Herrialde ezberdinetan emakumezkoen artean antsiolitiko eta hipnotikoen kontsumoa handiagoa izan zen. BDZ erabilienen artean diazepama eta lorazepama zeuden. 2006-2018 urteen artean EAEn kontsumitutako antsiolitiko-ontzien \% 73 eta hipnotikoen \% 66 emakumezkoek kontsumitu zituzten. Antsiolitikoen kasuan emakumezkoen artean saldutako ontzi kopurua 100 biztanleko, gizonezkoetan saldutakoa baino 1,09 aldiz handiagoa izan zen eta 0,87 aldiz handiagoa hipnotikoen kasuan. Psikofarmako guztiak kontuan hartutasaldutako ontzi kopurua handiagoa (\% 67) izan zen emakumezkoen artean, antipsikotikoen taldeansexuaren araberako desberdintasuna txikiena izan zelarik. Horrela, antipsikotikoen kontsumoarekin doituriko probabilitatea (Odds Ratio)kalkulatuta, emakumezkoen arteanantsiolitikoak kontsumitzekoagizonezkoen arteanbaino2,2 aldiz handiagoaeta hipnotiko sedagarriak kontsumitzekoa, berriz, 2 aldiz handiagoa izan zen.EAEn lorazepam farmakoa izan zen salduena.

Laburbilduz, EAEn ereantsiolitikoen eta hipnotikoen generoaren araberako kontsumoaren datuak bat datoz beste herrialdeetakoekin. Farmako salduenen artean lorazepamazegoen. Etorkizunean interesgarria litzateke datuak adinaren edota beste zenbait faktoreren arabera sailkatuta lortzea, horiek kontsumoan izan dezaketen eragina ikertu ahal izateko.

Gako-hitzak: antsiolitiko, hipnotiko, genero, kontsumo, Euskal Autonomia Erkidegoa

Bidalia: 352 - 21.02.28

Onartua: 2021.05.06

http://doi.org/10.26876/osagaiz.1.2021.359 


\section{Abstract}

Anxiety is a reaction to prevent adverse events but when it exceeds athreshold, it could be pathological. Insomnia consists of difficulty in falling asleep, maintaining sleep or waking up too early. To treat these disorders psychotropic drugs including benzodiazepines (BDZ) and hypnotics are used. In Spain, the consumption of psychotropic drugs is high.

The goals of this research were: 1) To analyze gender-based consumption of anxiolytics and hypnotics worldwide 2) To perform a gender-based field research of anxiolytics and hypnotics consumption in the Autonomous Community of the Basque Country (ACBC) between 2006 and 2018. To carry out the research, we performed systematic bibliographic search in five databases and we analyzed anxiolytics and hypnotics consumption data in the $A C B C$.

The consumption of anxiolytics and hypnotics was higher among women in different countries. Diazepam and lorazepam were the most used BDZ. In the $A C B C$, women consumed $73 \%$ of the anxiolytics and 66\% of the hypnotic's packages between 2006 and 2018. The number of anxiolytic and hypnotics packages sold per 100 inhabitants was 1.09 and 0.87 times higher among women, respectively. Whenthe whole group ofpsychotropic drugs was considered the number of packages sold was higher among women (67\%), being gender-based differences smaller in the antipsychotic group. Thus, when the probability of consumption adjusted with antipsychotic control (Odds ratio) was calculated, it was 2.2 fold higher among women for anxiolytics and 2 fold higher for hypnotics. In the $A C B C$, lorazepam was the most sold drug.

In summary, gender-based consumption, data of anxiolytics and hypnotics in the ACBC were consistent with those collected worldwide. Lorazepam was among the most sold drugs. In the future, it would be interesting to obtain data organized by age or other factors to study their involvement in consumption.

Keywords: anxiolytic, hypnotic, gender, consumption, The Autonomous Community of the Basque Country

\section{Sarrera}

Antsietatea etorkizuneko min edo ezbeharrei aurre egiteko erreakzio arrunta da,baina atalase bat gainditzen duenean patologikoa izan daiteke eta antsietate-nahasmenduakgerta litezke(1).Horietatik, antsietate-nahasmendu orokortua da lehen mailako arretan gehien azaltzen dena,eta populazio orokorrean \% 5eko prebalentziadu. Nahasmendu horigehiago gertatzen da (2:1) emakumezkoetan eta helduaroan(2).

Loezinakloak hartzeko, hura mantentzeko edota goiz esnatu eta berriz loak hartzeko ezintasunariegiten dio erreferentzia(3).Loezinaren nahasmenduak maizago gertatzen dira emakumezkoetan $(1,5: 1)$ eta ohikoagoak dira adinekoetan(4).Ohayon eta Sagales-ek 2010. urtean argitaratu zutenez, Espainiako populazioaren \% 20,8k gutxienez loezinaren sintoma bat pairatu zuen astean hiru gauez,eta prebalentzia emakumezkoetanhandiagoa izan zen(\% 23,9 vs \% 17,6)(5).

Antsietatearen eta loezinaren tratamendurako bentzodiazepinak (BDZ) eta hipnotiko sedagarriak erabiltzen dira batik bat (1. taula). BDZen eragin farmakologiko gehienak nerbio-sistema zentralean gertatzen dira, eta, dosiaren arabera, antsiolisia, eragin hipnotikoa zein sedazioa eragin dezakete. Antsiolitiko gisa, BDZak ez diren beste farmako batzuk ere erabiltzen dira, buspirona esaterako. Hipnotiko sedagarrien barnean, berriz, BDZez gain, Z-hipnotikoak daude. Farmako horiek potentzia handia eta bizi-erdi laburra daukate, baina ez dute eragin antsiolitikorik(6). Ebidentziaren arabera, antsiolitiko eta hipnotikoen preskripzioan hainbat faktorek eragiten dute: adinak(7),generoak 
(emakumezkoa izateak)(8),langabeziak edota pazienteak artatzeko dagoen denbora faltak, besteak beste(9).

1. taula: Antsietate eta loezinaren tratamendurako farmakoen sailkapena

\begin{tabular}{|l|l|}
\hline \multicolumn{1}{|c|}{ Antsiolitikoak } & \multicolumn{1}{c|}{ Hipnotikoak } \\
\hline $\begin{array}{l}\text { Bentzodiazepinak (GABA-A hartzaileetan } \\
\text { eragiten dute): diazepama, lorazepama, } \\
\text { alprazolama, bromazepama, klordiazepoxidoa. }\end{array}$ & $\begin{array}{l}\text { Bentzodiazepinak (GABA A hartzaileetan } \\
\text { eragiten dute):triazolama, lormetazepama. }\end{array}$ \\
\hline $\begin{array}{l}\text { Hartzaile serotonergikoetan eragiten duten } \\
\text { farmakoak: buspirona }\end{array}$ & $\begin{array}{l}\text { Hipnotiko ez-bentzodiazepiniko } \\
\text { sedagarriak: zolpidema, zopiklona. }\end{array}$ \\
\hline
\end{tabular}

European Study of Epidemiology of Mental Disorders-ek 2001-2002 urteen arteko datuen arabera argitaratu zuenez, Espainiako populazioaren \% 16k psikofarmakoren bat kontsumitu zuen eta erabilienak BDZak $(\% 11,4)$ izan ziren. Badirudi adinak eta generoak asoziazioa erakutsi zutela psikofarmakoen erabilerarekin(10). 2016an Carrasco-Carrido eta kolaboratzaileen ikerketaren arabera,Espainiako emakumezkoen artean psikofarmakoen erabilera handiagoa izan zen gizonezkoekin alderatuta,eta joera hori handituz joan zen adinean gora egin ahala (9). Hortaz, badirudi psikofarmakoen kontsumitzaile nagusienak emakumezkoak direla (8).

Era berean, 1998an argitaratutako artikulu batek frogatu zuen Estatu Batuetako kontsultetan emakumezkoek psikofarmako bat hartzeko zuten probabilitatea \% 55ekoa zela eta generoaren eta antsiolitiko bat hartzeko probabilitatearen artean erlazio zuzena zegoela(11).

Euskal Autonomia Erkidegoari (EAE) dagokionez, 2018ko irailean Droga-mendekotasunaren Euskal Behatokiakargitaratutako txostenaren arabera, populazioaren \% 26k bizitzako momenturen batean errezeta bidez lortutako BDZ eta Z-hipnotiko bat kontsumitu zuen(12).

\section{Helburuak}

Aurrekari horiek guztiak kontuan izanik, interesgarria litzateke generoaren araberako antsiolitikoen eta hipnotiko sedagarrien kontsumoaren joera nazioartean zein Euskal Autonomia Erkidegoan (EAE) aztertzea. Horregatik, lan honen helburu zehatzak honakoak dira:

1. Nazioartean gertatzen den antsiolitikoen eta hipnotiko sedagarrien kontsumoaren generoaren araberako analisia egitea.

2. EAEn 2006-2018 urteen artean gertatzen den antsiolitikoen eta hipnotiko sedagarrien generoaren araberako kontsumoaren eremu- edo landa-ikerketa egitea.

\section{Material eta metodoak}

\subsection{Artikuluen bilaketa eta nazioarteko datuen erauzketa eta analisia}

Nazioartean gertatzen den kontsumoari buruzko artikuluen bilaketa eta datuen erauzketa egiteko 5 datu-base ezberdin erabili ziren: PubMed, Google Scholar, Trip Database, Embase (sciencedirect) eta Cochrane. Bilaketa PICO metodoa erabiliz egin zen: populazioa (population) antsiolitiko edo hipnotiko sedagarriak hartzen zituzten pazienteak izan ziren, interbentzioa (intervention) farmakoen erabilera edo kontsumoa izan zen, konparazioa (comparison) generoa izan zen eta emaitza (outcome), aldiz, desberdintasuna edo diferentzia.

Behin bilaketa eginda, artikuluak baztertzeko eta onartzeko irizpideak aplikatu ziren. Honakoak izan ziren baztertze-irizpideak: antsiolitiko edo hipnotiko sedagarriei buruzko infomaziorik ez agertzea, gure helburua ez zen beste bat aztertzea, bentzodiazepinen despreskripzioa ikertzea, artikulua ezin 
eskuratu ahal izatea, generoaren araberako analisirik ez egitea, farmakoen kontsumoarekin erlazionatutako faktoreak ikertzea, orokorrean psikofarmakoak ikertzea edota emaitzak portzentaje, prebalentzia edo odds ratio (OR) gisa ez azaltzea.

\subsection{EAEko datuen bilketa eta analisia}

Euskal Autonomia Erkidegoko (EAE) antsiolitiko eta hipnotiko sedagarrien erabileraren datuak erauzteko, eremu- edo landa-ikerketa egin zen Eusko Jaurlaritzako Osasun Saileko Farmazia Zuzendaritzaren bidez lortutako datuak abiapuntutzat hartuz. Modu horretara, 2006tik 2018ko abuztura arte saldutako psikofarmakoen ontzi kopurua lortu genuen. Datu horiek, generoka (gizonezko, emakumezko) zein urteka (2006tik 2018ko abuztura) banatuta lortu ziren. Talde farmakologikoak sailkatzeko, Anatomical Therapeutic Chemical (ATC) izeneko sailkapen-sistema erabili zen: N05A antipsikotikoak, N05B antsiolitikoak, N05C hipnotiko eta sedagarriak, N06A antidepresiboak, N06B psikoestimulatzaile eta nootropikoak eta N06D dementziaren aurkako farmakoak. Nootropikoak funtzio mentala estimulatzen duten substantziak dira, besteak beste, kognizioa, oroimena, motibazioa, arreta zein kontzentrazioa handitu dezaketenak (adib. garuneko aktibatzaileak, basozabaltzaile periferikoak...).

Gure helburua lortzeko, antsiolitikoak (N05B) eta hipnotiko sedagarriak (N05C) kontuan hartzeaz gain, beste psikofarmakoen kontsumoa ere analizatu genuen, antipsikotikoena (N05A) eta dementziaren aurkako farmakoena (N06D) besteak beste. Alde batetik, psikofarmakoen talde bakoitzean emakumezkoek eta gizonezkoek kontsumitutako ontzien portzentajeak kalkulatu genituen. Horretaz gain, populazioari egokitutako psikofarmakoen kontsumoa kalkulatu genuen, hau da, psikofarmakoen talde bakoitzean saldutako ontzi kopurua 100 biztanleko (portzentajea) bai emakumezkoetanzein gizonezkoetan. Horrela, emakumezkoek gizonezkoek baino ontzi kopuru gehiago kontsumitzen zituzten aztertu genuen. Aztertutako epean (2006-2018 artean) EAEn zeuden gizon eta emakume kopurua jakiteko, 18 urtetik gorako populazio-datuak lortu genituen Estatistikako Institutu Nazionalaren (EIN) bidez(13). Prozedura berari jarraitu genion urtez urteko farmakoen kontsumoa analizatzeko, hau da, bi sexuetan urte bakoitzeko populazioa eta ontzi kopurua hartu genituen kontuan. Bestetik, emakume eta gizonen antsiolitiko eta hipnotiko sedagarrien kontsumoaren arteko konparazioak egiteko ORak kalkulatu genituen erreferentziatzat (kontrola) antipsikotikoak hartuta. Kontrol gisa antipsikotikoen taldea aukeratu genuen psikofarmakoen artean talde horrek sexuaren araberako desberdintasunik txikienak aurkezten zituelako. Horrela, ORak kalkulatuta emakumezkoek gizonezkoek baino antsiolitiko eta hipnotiko sedagarri gehiago kontsumitzeko probabilitate handiagoa zuten aztertu genuen.

Irudiak eta analisi estatistikoak egiteko, Excel programa eta GraphPad Prism izeneko programa erabili ziren, eta Fisherren test zehatza eta $\chi^{2}$ karratuaren testak aplikatu ziren.

\section{Emaitzak}

\subsection{Antsiolitiko eta hipnotiko sedagarrien kontsumoaren generoaren araberako analisia nazioartean}

PubMed-en bilaketa egiteko PICO metodoa erabili zen, termino askeak eta MeSH terminoak haien artean konbinatu ziren OR eta AND antolatzaileak erabiliz. Modu horretara, 675 artikulu lortu ziren. Ondoren, "humans" (gizakiak), "english" (ingelesa), "spanish" (gaztelania), "female" (emakumezkoak) eta "male" (gizonezkoak) iragazkiak erabili ziren, eta 586 artikulu bildu.

Google Scholar, Embase eta Cochrane datu-baseetan erabilitako bilaketa-algoritmoa: ("Benzodiazepines" OR "Hypnotics and sedatives") AND "Prescriptions" AND ("Sex characteristics" OR "Gender identity") AND ("Difference" OR "Distribution") izan zen. Google Scholar-en, artikuluak ingelesez eta gaztelaniaz lortzeko iragazkia erabili zen. Modu horretara, 80 artikulu lortu ziren Google Scholar-en, 56 artikulu Embase-n eta 14 artikulu Cochrane-n. 
rip Database-n, aldiz, PICO eskema erabiliz, P ("Benzodiazepines" OR "Hypnotics and sedatives"), I ("Prescriptions"), C ("Sex characteristics" OR "Gender identity") eta O ("Difference" OR "Distribution"), 14 artikulu lortu ziren.

Guztira, 750 artikulu lortu ziren analisirako. Artikulu horiei aipaturiko baztertze-irizpideak aplikatu zitzaizkien. Horrela, 673 artikulu kanpoan geratu ziren izenburuak irakurri ondoren, 51 artikulu laburpenak irakurri ondoren, 2 artikulu eskuratzeko ezintasunagatik eta 14 artikulu, testu osoa irakurri ondoren. Beraz, 740 artikulu baztertuak izan ziren eta zeharkako 10 artikulu bildu ziren analisirako.Hauek izan ziren erauzitako datuak:

Kaspersen eta kolaboratzaileek argitaratutako ikerketak dioenez, Norvegian 2016an, saldutako hipnotiko sedagarrien $\% 58$ eta antsiolitikoen $\% 60$ emakumezkoen artean izan zen(14).

Hassan eta kolaboratzaileek 2016. urtean argitaratu zutenez, Ingalaterran emandako antsiolitiko eta hipnotikoen preskripzioa \% 2,5ekoa izan zen emakumezkoen artean, eta gizonezkoen artean, berriz, $\% 1,4$ koa. Farmako erabilienak zopiklona (\% 32,3) eta diazepama $(\% 21,5)$ izan ziren (15).

Hall eta kolaboratzaileek 2010. urtean Estatu Batuetan (Bostonen zehazki) egindako ikerketaren arabera, populazioan emandako BDZen prebalentzia adinarekin doituz (\% $95 \mathrm{Cl}) \% 5$,6koa $(4,6-6,8)$ izan zen. Zehazki, emakumezkoetan \% 7,3koa izan zen eta gizonezkoetan \% 3,7koa (16).

Kanadan, Quinn eta kolaboratzaileek egindako ikerketa baten arabera, emakumezkoen \% 6,9k eta gizonezkoen \% 4,0k BDZ bat erabili zuten 1992an, eta erabiliena oxazepama izan zen(17). 2010ean, Cunningham eta kolaboratzaileek frogatu zuten emakumezkoa izateak BDZ bat hartzeko 1,34 aldiz arrisku handiagoa zuela(18).

Kokkevi eta kolaboratzaileek 2008an Europako 31 herrialde ezberdinen informazioa erabilita egindako ikerlanean populazioaren $\% 6,4 \mathrm{k}$ gutxienez bizitzan behin antsiolitiko edo sedagarri bat hartu zuela adierazi zuten. Horietatik \% 6,6 emakumezkoak izan ziren eta \%6,2 gizonezkoak. Ikerketan parte hartu zuten herrialdeen emakumezko/gizonezko arteko OR orokorra 1,1 (1,1-1,2) izan zen, zeina estatistikoki esanguratsua izan zen(19).

Alvarenga eta kolaboratzaileek 2007. urtean argitataratu zutenez, Brasilen BDZen kontsumoaren prebalentzia\% 21,7koa izan zen, emakumezkoen artean gizonezkoen artean baino handiagoa (\% 26,7 eta \% 14). Horietatik antsiolitikoak \% 76,8 eta hipnotiko sedagarriak \% 10,6 izan ziren eta erabilienak bromazepam $(\% 35,6)$ eta diazepam $(\% 22,5)$ farmakoak izan ziren(20).

Nomura eta kolaboratzaileek Japonian 2006an argitaratu zutenez, pazienteen \% 15ek BDZ bat hartu zuen, eta horietatik\% 61 emakumezkoak eta \% 39 gizonezkoak izan ziren. Emakumezkoa izatea, estatistikoki esanguratsua izan zen BDZak hartzeko unean(21).

Petit eta kolaboratzaileek 1994. urtean Belgikan egindako ikerketaren aburuz, emakumezkoen $\% 46,5 \mathrm{ek}$ eta gizonezkoen \% 42,7k BDZ bat hartu zuten (ezberdintasun estatistikoki esanguratsua). Hipnotiko sedagarriei dagokienez, ezberdintasun estatistiko hori handiagoa izan zen, gizonezkoen $\%$ 27,7k eta emakumezkoen \% 33,3k hipnotiko sedagarri bat hartubaitzuten(22).

Van der Waals eta kolaboratzaileek 1993. urtean Holandan aztertutako laginean gizonezkoen \% 31k eta emakumezkoen \%69k BDZ bat hartu zutela ikusi zuten. Preskripzio horrek gora egin zuen adinarekin. Generoagatiko doikuntza burutu ondoren ere, emakumezkoa izateak BD Zahartzeko arriskua handitzen zuela ikusi zuten (RR 1.68-1.92)(23).

\subsection{Antsiolitiko eta hipnotiko sedagarrien generoaren araberako kontsumoaren analisia Euskal Autonomia Erkidegoan}

4.2.1. Antsiolitikoen eta hipnotiko sedagarrien eta beste psikofarmakoen kontsumoaren datu orokorrak 2006-2018 urteen artean 
2006-2018 artean EAEn 49.831.491 psikofarmako-ontzi saldu ziren. Horietatik, erdia baino gehiago, hau da, 33.546.759 ontzi (\% 67) emakumezkoen artean saldu ziren eta 16.284 .732 ontzi (\% 33) gizonezkoen artean.

Psikofarmako guztien artean kontsumituenak antsiolitikoak izan ziren, 20.347 .292 ontzi saldu zirelarik (psikofarmako-ontzi guztien \% 41). Horietatik, 6.263 .568 ontzi gizonezkoetan eta 14.083.724 ontzi emakumezkoen artean saldu ziren. Hortaz, antsiolitiko-ontzien\% 70 emakumezkoen artean eta $\% 30$ gizonezkoen artean saldu ziren.

Psikofarmakoen artean bigarren talde farmakologikorik kontsumituena antidepresiboena izan zen, eta 13.196.725 ontzi saldu ziren (psikofarmako-ontzi guztien \% 26). Horietatik, 3.672.195 ontzi emakumezkoen artean eta 9.524.530 ontzi gizonezkoen artean saldu ziren. Hau da, antidepresiboontzi guztien\% 28 gizonezkoen artean eta \% 72 emakumezkoen artean saldu ziren.

Aztertutako epean, hirugarren talde farmakologikorik kontsumituena hipnotiko sedagarriena izan zen, eta 8.595.854 ontzi saldu ziren (psikofarmako-ontzi guztien \% 17). Horietatik, 2.855 .340 ontzi gizonezkoen artean eta 5.740 .514 ontzi emakumezkoen artean saldu ziren. Hipnotiko sedagarrien ontzien \% 66 emakumezkoen artean eta \% 33 gizonezkoen artean kontsumitu ziren.

Laugarren talde farmakologikorik kontsumituena antipsikotikoena izan zen, saldutako psikofarmakoontzi guztien\% 9(ontzi kopuru osoa 4.406.359). Gizonezkoen artean 2.104.165 ontzi eta emakumezkoen artean 2.302.194 ontzi saldu ziren. Antipsikotikoen ontzi kopuru osoaren \%52 emakumezkoen artean saldu zen eta \% 47, aldiz, gizonezkoen artean.

Bostgarren talde farmakologikorik kontsumituena, psikoestimulatzaile eta nootropikoena izan zen, eta 1.905.716 ontzi saldu ziren (psikofarmako-ontzi guztien \% 4). Horietatik, 931.320 ontzi gizonezkoen artean eta 974.396 ontzi emakumezkoen artean saldu ziren. Psikoestimulatzaileeta nootropiko ontzien \% 49 gizonezkoen artean eta \% 51 emakumezkoen artean kontsumitu ziren.

Azkenik, dementziaren aurkako farmakoak dauzkagu. Horiei dagokienez, 1.379.545 ontzi saldu ziren guztira, psikofarmakoen \% 3 hain zuzen ere. Gizonezkoen artean 458.144 ontzi eta emakumezkoen artean 921.401 ontzi saldu ziren. Dementziaren aurkako farmako-ontzien \% 66 emakumezkoen ontziak izan ziren eta \% 33 gizonezkoenak.

Psikofarmako guztien artean honako talde farmakologiko hauek aukeratu genituen generoaren araberako kontsumoan ea desberdintasunik zegoen sakonago aztertzeko: antsiolitikoak, hipnotiko sedagarriak, dementziaren aurkako farmakoak eta antipsikotikoak.

Lau talde horietan emakumezkoek kontsumitutako ontzi kopurua gizonezkoena baino handiagoa ote zen analizatzeko, eta balioak estatistikoki konparatzeko, urte-epe horretan gizartean zeuden emakumezkoen eta gizonezkoen kopurua jakitea ezinbestekoa zen. Datu horiek lortzeko, EINen kontsultatu eta datuen bateraketa egin zen: 2006-2018 urteetan 12.242 .945 emakume eta 11.401.612 gizonezko zeuden.

Antipsikotikoei dagokienez, emakumezkoen artean kontsumitu zen antipsikotiko ontzi kopurua 100 biztanleko gizonezkoen artean baino 0,02 aldiz handiagoa izan zen. Dementziaren aurkako farmakoei dagokienez, aldiz, emakumezkoen artean kontsumitu zen ontzi kopurua 100 biztanleko gizonezkoen artean baino 0,87 aldiz handiagoa izan zen. Antsiolitikoei dagokienez, emakumezkoen artean kontsumitu zen ontzi kopurua 100 biztanleko gizonezkoen artean baino 1,09 aldiz handiagoa izan zen eta emakumezkoen artean kontsumitu zen hipnotiko sedagarrienontzi kopurua 100 pertsonako gizonezkoen artean baino 0,87 aldiz handiagoa izan zen (1. irudia). Gizonezkoen eta emakumezkoen arteko desberdintasun horiek estatistikoki esanguratsuak izan ziren, baina antipsikotikoetan generoaren arteko ezberdintasun hori arinki esanguratsua izan zenez,farmako talde hori kontrol gisa aukeratu zen hurrengo analisietarako. 
1. irudia. 2006-2018 urteen artean kontsumitutako antipsikotikoen, dementzia aurkakoen, antsiolitikoen eta hipnotiko sedagarrien ontzi kopuruen portzentajea generoaren arabera. Lau talde farmakologikoetan emakumezkoek gizonezkoek baino ontzi gehiago kontsumitu zituzten eta ezberdintasun hori estatistikoki esanguratsua izan zen. ${ }^{*} p<0,05$ gizonezkoekin konparatuta Fisherren test zehatzaren bidez.

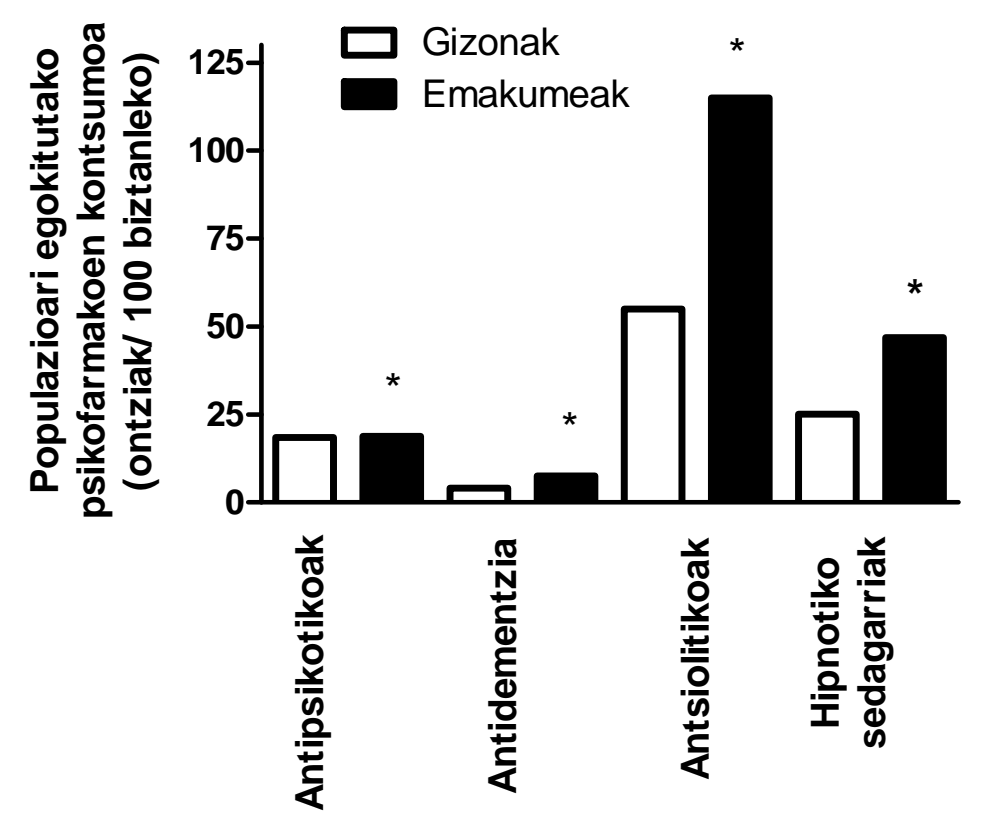

4.2.2. Antsiolitiko eta hipnotiko sedagarrien urtez urteko kontsumoaren datu orokorren azte

Datuak urtez urte aztertuz gero, urte guztietan emakumezkoen artean gizonezkoen artean baino antsiolitiko eta hipnotiko sedagarrien ontzi gehiago saldu zirela ikusi zen, eta generoaren arteko ezberdintasun hori urte guztietan estatistikoki esanguratsua izan zen $(p<0,05)$ ( 2 . irudia). Horrela, 2006. urtean emakumezkoen artean kontsumitutako antsiolitiko eta hipnotiko sedagarrien ontzi kopurua 100 biztanleko, gizonezkoen artean baino 0,96 eta 0,78 aldiz handiagoa izan zen,hurrenez hurren,eta 2007. urtean aldiz, 0,94 eta 0,8 aldiz handiagoa. 2008. urtean, emakumezkoen artean kontsumitutako antsiolitiko eta hipnotiko sedagarrien ontzi kopurua 100 biztanleko, gizonezkoen artean baino 1,04 aldiz handiagoa eta 0,84 aldiz handiagoa izan zen, hurrenez hurren, eta 2009an 1,31 eta 1 aldiz handiagoa. 2010, 2011 eta 2012an emakumezkoen artean kontsumitutako antsiolitikoen ontzi kopurua 100 biztanleko, gizonezkoekin alderatuta 1,3 aldiz handiagoa izan zen (2A. irudia). Hipnotikoei dagokienez, aldiz, kontsumoa 2010ean 1,01; 2011an 1,04 eta 2012an 1,02 aldiz handiagoa izan zen. 2013 urtean, emakumezkoen artean kontsumitutako antsiolitiko eta hipnotiko sedagarrien ontzi kopurua 100 biztanleko, gizonezkoen artean baino 1,24 eta 0,97 aldiz handiagoa izan zen. 2014 urtean 1,05 eta 0,85 aldiz handiagoa eta 2015ean 1,01 eta 0,82 aldiz handiagoa, hurrenez hurren. 2015. urteari dagokionez, emakumezkoen artean kontsumitutako antsiolitiko eta hipnotiko sedagarrien ontzi kopurua 100 biztanleko, gizonezkoen artean baino 1,01 eta 0,82 aldiz handiagoa izan zen, 2016an 1 aldiz eta 0,8 aldiz handiagoa, eta 2017an 0,98 eta 0,79 aldiz handiagoa, hurrenez hurren. Azkenik, 2018an emakumezkoen artean kontsumitutako antsiolitiko eta hipnotiko sedagarrien ontzi kopurua 100 biztanleko, gizonezkoekin alderatuta 0,34 eta 0,77 aldiz handiagoa izan zen, hurrenez hurren (2B. irudia). 
2. irudia.2006-2018 urteen artean urtez urte saldutako antsiolitikoen (A) eta hipnotiko sedagarrien (B) ontzien portzentajea emakumezkoen eta gizonezkoen artean. Urte guztietan, emakumezkoen artean gizonezkoen artean baino kontsumo handiagoa egon zen, eta ezberdintasun hori esanguratsua izan zen. ${ }^{*} \mathrm{p}<0,05$ gizonezkoekin alderatuz Fisherren test zehatza erabilita.

A
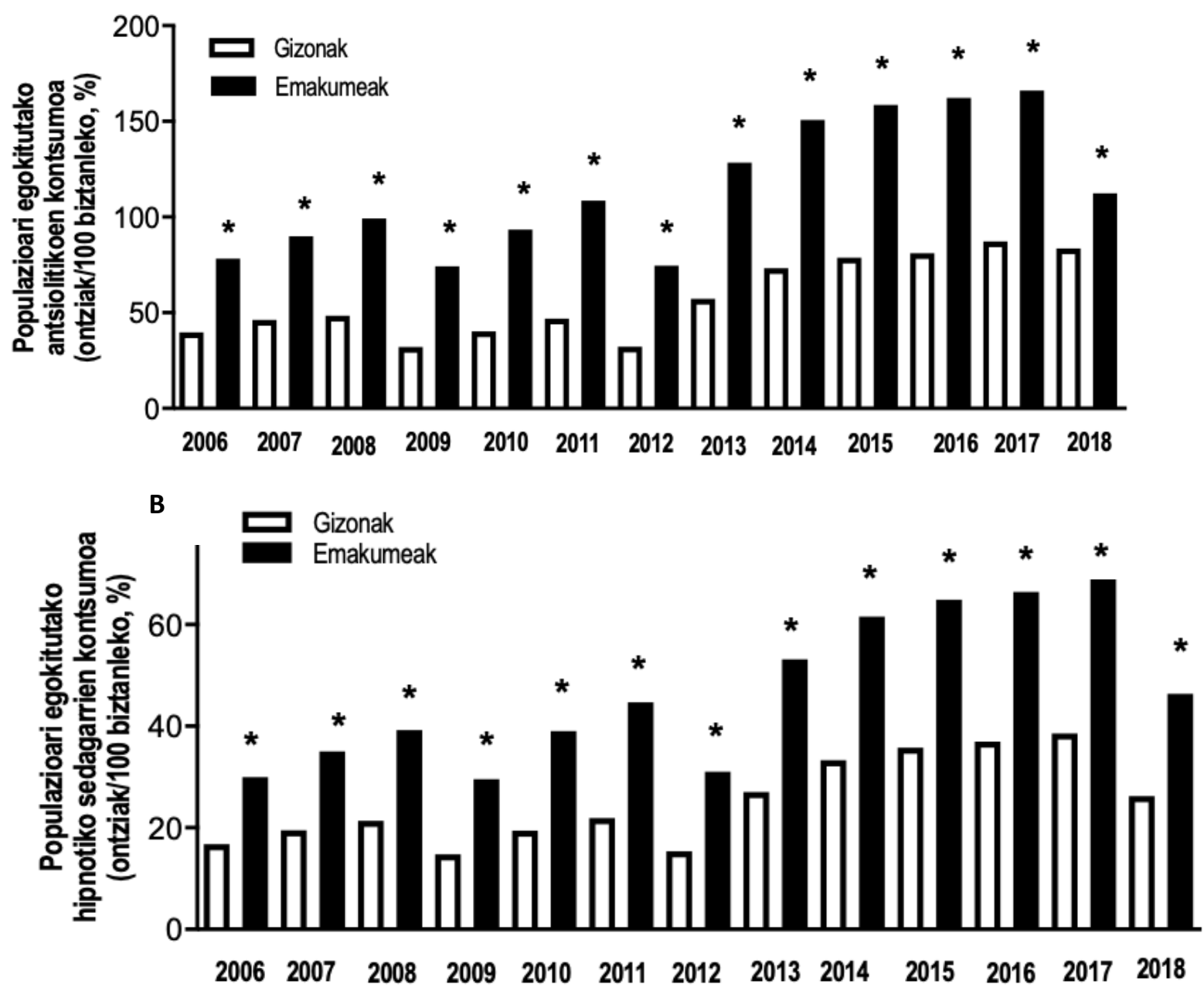

4.3. Antsiolitiko eta hipnotiko sedagarrien generoaren araberako kontsumoa EAEn kontroltaldearekin konparatuta

\subsubsection{Antsiolitiko eta hipnotiko sedagarrien kontsumoa2006-2018 urteetan}

Antsiolitiko eta hipnotiko sedagarrien emakumezkoen arteko kontsumoa gizonezkoen artekoarekin konparatzeko, ORa kalkulatu zen erreferentziatzat antipsikotikoak hartuta (kontrola). Antsiolitikoen kontsumoaren emakumezkoen ORa gizonezkoekikoeta kontrol-taldearekindoituta (antipsikotikoak) 2,24(2,25-2,25, \% $95 \mathrm{Cl})$ izan zen (3. irudia). Beraz, emakumezkoek gizonezkoek baino 2,2 aldiz probabilitate handiagoa zuten antsiolitikoak kontsumitzeko. Hipnotiko sedagarrien kontsumoaren emakumezkoen ORa gizonezkoekiko eta kontrol-taldearekin doituta 2,01 (2,007-2,014, \% $95 \mathrm{Cl})$ izan zen. Hau da, emakumezkoek 2 aldiz probabilitate handiagoa izan zuten hipnotiko sedagarriak kontsumitzeko (3. irudia). 
3. irudia.Antsiolitiko eta hipnotiko sedagarrien kontsumoaren emakumezkoen odds ratio-a gizonezkoekiko eta kontrol-taldearekin konparatuta (antipsikotikoak). $p^{*}<0,05$ Fisherren test zehatza erabilita.

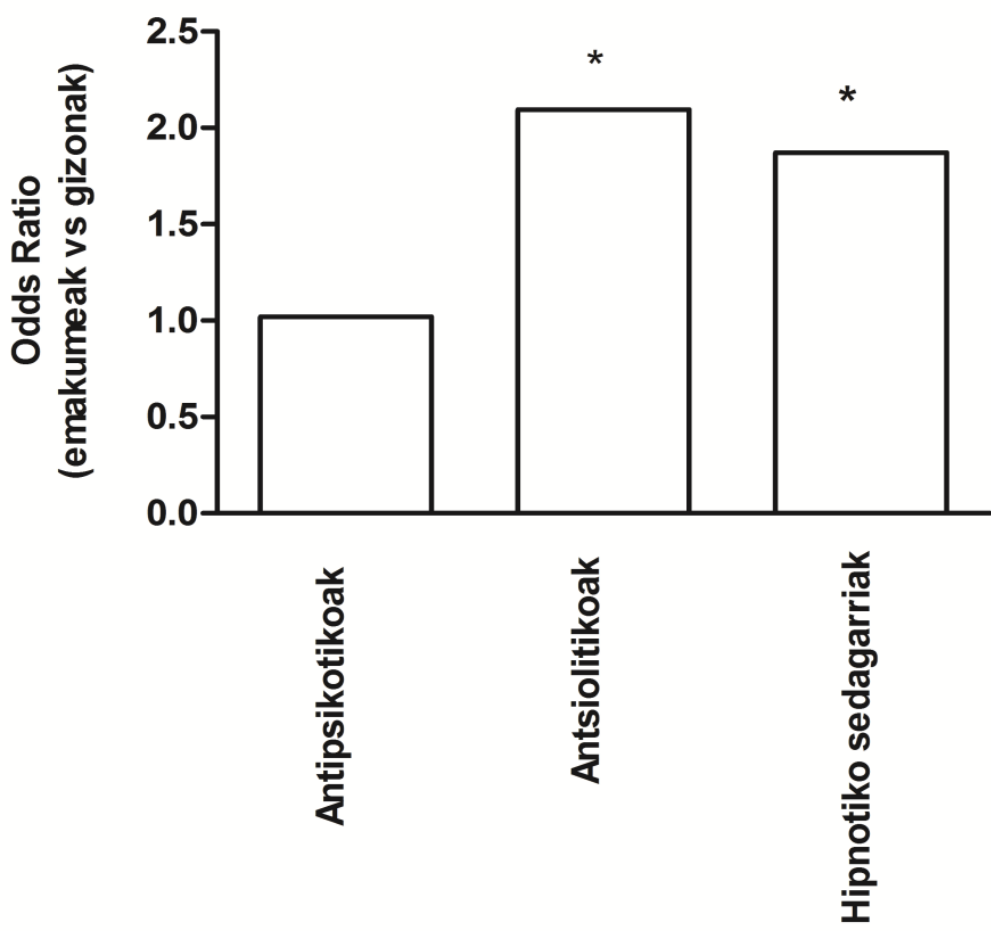

Kontsumitutako farmako antsiolitiko zehatzei erreparatzen badiegu, oro har, emakumezkoek antsiolitiko guztiak kontsumitzeko probabilitate handiagoa izan zuten gizonezkoek baino kontrolarekin alderatuz, klordiazepoxido farmakoa salbu $(p<0,05)$. Horrela, emakumezkoek 3,6 aldiz probabilitate handiagoa izan zuten klotiazepama kontsumitzeko gizonezkoek baino kontrolarekin alderatuz. Horrez gain, 3 aldiz probabilitate handiagoa izan zuten pinazolama hartzeko, 2,8 aldiz probabilitate handiagoa diazepama hartzeko eta 2,7 aldiz probabilitate handiagoa bromazepama hartzeko. Emakumezkoek, 2 aldiz probabilitate handiagoa izan zuten quetazolama, lorazepama, halazepama, klorazepato dipotasikoa, potasio klorazepatoa edota diazepama hartzeko, kontrolarekin alderatuz. BDZa ez den buspironari dagokionez, emakumezkoek 1,2 aldiz probabilitate handiagoa izan zuten gizonezkoek baino hori kontsumitzeko eta 2,1 aldiz handiagoa hidroxizina kontsumitzeko (4A. irudia).

Kontsumitutako farmako hipnotiko zehatzei erreparatuz, oro har, emakumezkoen artean hipnotiko guztiak kontsumitzeko probabilitatea handiagoa izan zen gizonezkoen artean baino kontrolarekin alderatuz, glutamato magnesiko bromhidratoaren kasuan izan ezik $(p<0,05)$. BDZak diren hipnotiko sedagarriei dagokienez, emakumezkoek 2-2,4 aldiz probabilitate handiagoa izan zuten triazolama, lorprazolama, lormetazepama eta brotizolama kontsumitzeko gizonezkoek baino kontrolarekin alderatuz. Horrez gain, 1,9 aldiz probabilitate handiagoa izan zuten quazepama hartzeko, 1,7 aldiz probabilitate handiagoa flurazepama hartzeko, eta 1,5 aldiz probabilitate handiagoa flurazepama eta midazolama hartzeko. Hipnotiko sedagarrien taldearen barruan dauden Z-hipnotikoei dagokienez, emakumezkoek, 2,2 aldiz probabilitate handiagoa izan zuten zolpidema hartzeko kontrolarekin alderatuz. Horrez gain, 1,9 aldiz probabilitate handiagoa izan zuten zopiklona eta 1,8 aldiz probabilitate handiagoa zaleplona kontsumitzeko. BDZak eta Z-hipnotikoak ez diren farmakoei dagokienez, emakumezkoek 1,1 aldiz probabilitate handiagoa izan zuten klometiazola kontsumitzeko (4B. irudia). 
4.irudia. Farmako antsiolitikoen (A) eta hipnotiko sedagarrien (B) emakumezkoen ORa gizonezkoekin konparatuta kontrol-taldearekiko doituta (antipsikotikoak). Klordiazepoxido antsiolitikoa eta glutamato magnesiko bromhidratoa izan ezik, gainerako farmako guztiak gehiago kontsumitu ziren emakumezkoen artean gizonezkoen artean baino. ${ }^{*} p<0,05$ antipsikotikoekin alderatuz Fisherren test zehatzaren bidez.

A
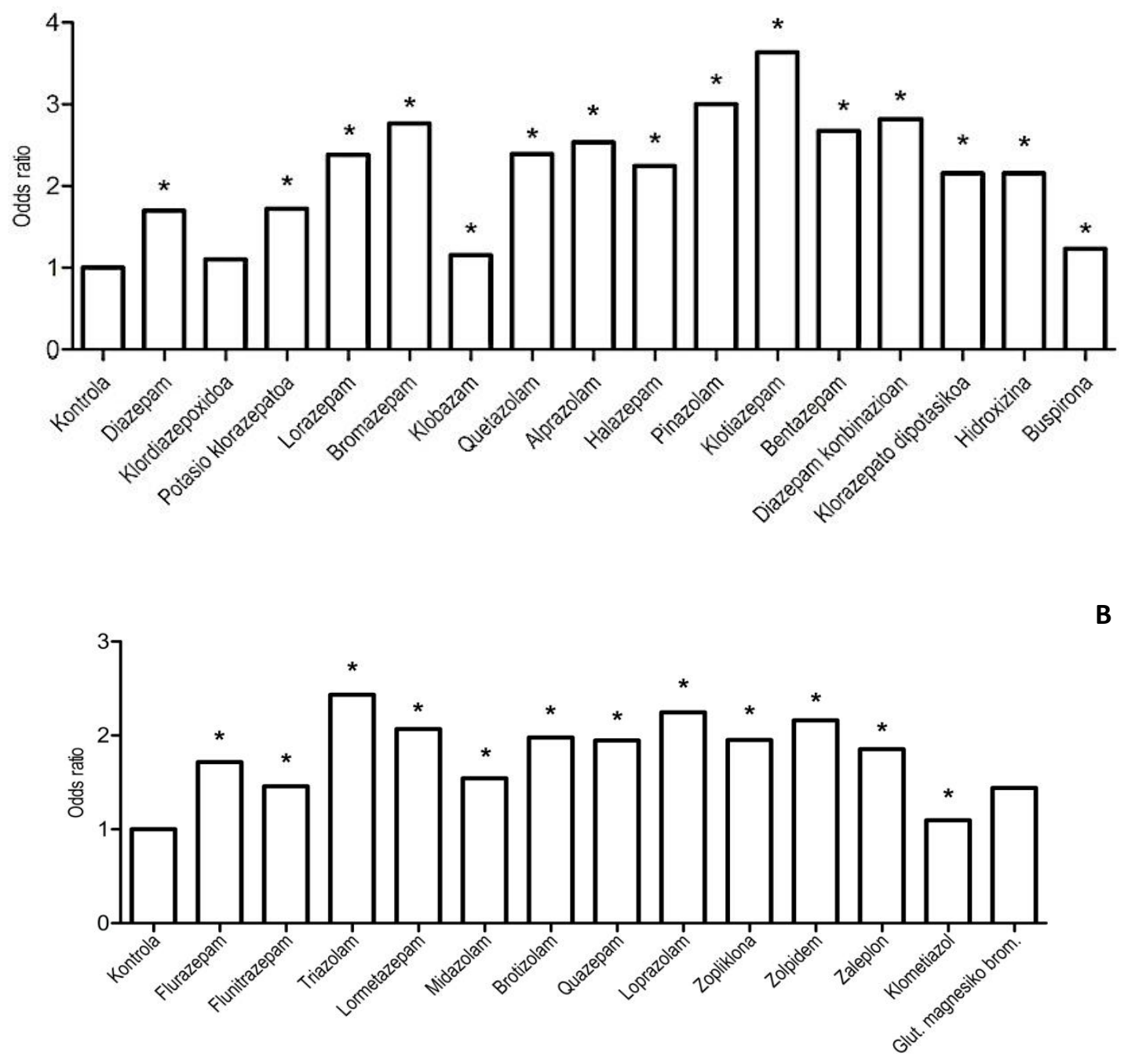

\subsubsection{Antsiolitiko eta hipnotiko sedagarrien urtez urteko kontsumoaren eta kontrolaren arteko konparazioa}

2006-2018 urteen artean emandako antsiolitiko eta hipnotiko sedagarrietatik gehien saldu zirenak bai gizonezkoen artean bai emakumezkoen arteanlorazepama, lormetazepama eta alprazolama izan ziren.

Urte-tarte horretan, 9.238.332 lorazepam-ontzi saldu ziren, zeinetatik 6.507 .170 ontzi emakumezkoen artean eta 2.731.162 gizonezkoen artean saldu ziren. Erabilitako lorazepam-ontzi guztietatik \% 70 emakumezkoen arteaneta \% 30 gizonezkoen artean eman ziren. Horrez gain, 20062018 artean EAEn, 5.740.078 lormetazepam-ontzi saldu ziren: 3.871.184 emakumezkoen artean eta 1.868.894 gizonezkoen artean. Erabilitako lormetazepam-ontzi guztien \% 67 emakumezkoen artean eta \% 32 gizonezkoen artean eman ziren. Azkenik, EAEn 2.950 .438 alprazolam-ontzi saldu ziren: 2.115.791 emakumezkoen artean eta 834.647 gizonezkoen artean. Beste era batera esanda, alprazolam-ontzi guztien \% 72 emakumeen artean eta \% 28 gizonezkoen artean saldu ziren. 


\section{Eztabaida}

Emakumezkoek gizonezkoek baino antsiolitiko eta hipnotiko sedagarrien kontsumo handiagoa izan zutela ikusi zen Europako, Ameriketako eta Asiako zenbait herrialdetan (14-23). Farmako erabilienen artean, Ingalaterran diazepama (15), edota, Brasilen bromazepana daude (20). EAEn ere, emakumezkoen antsiolitiko zein hipnotiko sedagarrien kontsumoa gizonezkoena baino handiagoa izan zela ikusi zen 2006-2018 urteen artean, eta joera hori urte guztietan zehar esanguratsua izan zen. Emakumezkoek antsiolitikoak kontsumitzeko izan zuten probabilitatea gizonezkoena baino 2,2 aldiz handiagoa izan zen eta hipnotiko sedagarriak kontsumitzekoa 2 aldiz handiagoa kontrola erreferentziatzat hartuta. EAEn farmako salduenak lorazepama, lormetazepama eta alprazolama izan ziren.

Aztertutako artikuluetan, herrialdez herrialdeko portzentaje eta prebalentziak aldatuz doaz: Estatu Batuen BDZen kontsumoaren prebalentziaemakumezkoetan \% $7 \mathrm{koa}$ eta gizonezkoetan \% 3,7koa izan zen(17), eta Brasileko ikerketan, adibidez, BDZen kontsumoaren prebalentzia emakumezkoetan $\% 26 \mathrm{koa}$ eta gizonezkoena \% 14koa izan zen(20). Nazioartean gertatzen den antsiolitiko eta hipnotiko sedagarrien kontsumoaren portzentajea oso aldakorra bada ere, oro har, emakumezkoen kontsumoa askoz handiagoa da. Portzentajeetan dagoen desberdintasun horren oinarrian, ikerketa bakoitzean erabilitako laginen tamaina ezberdina, aztertutako urteen desberdintasuna zein herrialde bakoitzaren egoera aipa daitezke. Gure ikerlanarekiko aipagarri den beste desberdintasun bat aurkeztutako datu mota litzateke. Izan ere, nazioarteko ikerlan askotan prebalentzia-datuak (esaterako Estatu Batuetan (17) edota Brasilen (20) aurkezten dira eta gure kasuan portzentajeak eta ORak kalkulatu ditugu saldutako ontzi kopuruak abiapuntutzat hartuta.

Farmako talde bakoitzaren barnean gertatzen den sexu-banaketari dagokionez, esan daiteke EAEn 2006-2018 artean saldutako antsiolitikoen \% 73 eta hipnotiko sedagarrien \% 66 emakumezkoek hartu zituztela. Ikertutako herrialdeetan ere, antzeko joera hau ikusi da: Norvegian, erabilitako antsiolitikoen \% 60 eta hipnotiko sedagarrien \% 58 emakumezkoek hartu zituzten (14), eta Japoniako artikuluaren arabera, emandako BDZ guztietatik \%61 emakumezkoak eta \%39 gizonezkoak izan ziren (21).

Aztertutako ikerketa batzuetan, eta baita gure kasuan ere, emakumezkoek gizonekin alderatuta antsiolitiko edo hipnotiko sedagarriak kontsumitzeko duten probabilitatea kalkulatu zen OR bidez. Gure kasuan, antsiolitikoen emakume/gizon ORa 2,2koa izan zen, eta hipnotiko sedagarrien ORa, aldiz, 2koa. Nazioarteko datuei begiratuz gero, esaterako, Kanadan emakumezkoek 1,34 aldiz probabilitate handigoa izan zuten gizonezkoek baino BDZ bat hartzeko (18), eta Japonian, berriz, 1,6 aldiz probabilitate handiagoa (21). Kokkevi eta kolaboratzaileek argitaratutako artikuluaren arabera, oro har, Europako neskek mutilek baino 1,1 probabilitate handiagoa erakutsi zuten lasaigarri edo sedagarri bat hartzeko (19).

EAEn, 2006-2018 arteko populazio osoa kontuan izanda, EAEko emakumeek gizonezkoek baino \% 109 antsiolitiko eta \% 87 hipnotiko sedagarrien ontzi gehiago kontsumitu zituzten. Emakumezkoek ontzi gehiago kontsumitzeko joera hori 2006-2018 artean aztertutako urte guztietan ikusi zen bi farmako talde hauetan. Antsiolitikoen generoaren arteko ezberdintasun handiena 2009. urtean gertatu zen eta hipnotiko sedagarriena 2011. urtean. Horrekin erlazioa izan dezake 2008. urtean hasi zen krisialdi ekonomikoak eta horrek ekarrizuen farmako hauen preskripzioarekin erlazionatutako faktoreen handitzeak. Aldiz, bi farmako talde hauengeneroaren arteko ezberdintasun txikienak 2018. urtean lortu ziren. Hori horrela izan daiteke urte horretan abuztura arteko datuak soilik edukitzearen ondorioz.

Farmakoei dagokienez, EAEko farmako erabilienak (lorazepama, lormetazepama eta alprazolama) nazioartean ere gehien erabiltzen direnen artean daudela ikusi zen, bereziki lorazepama. Orokorrean, farmako hauen kontsumoa konparatzea zaila da, ikerketa bakoitzak kontsumoa adierazteko erabiltzen dituen datuak modu ezberdinean azaltzen direlako.

Urteetan zehar hainbat egile emakume eta gizonezkoen arteko antsiolitiko eta hipnotikoen

$$
\text { Osagaiz - 2021 - 5. bolumena - 1. zk.- } 95
$$


kontsumoaren desberdintasunaren zergatia azaltzen saiatu dira. Esaterako, Romo eta kolaboratzaileek egindako ikerketa kualitatiboak proposatzen zuenez, emakumezkoen kontsumo honen atzean, ondoez psikologikoak somatizatzeko eta arrazoi horregatik kontsultara joateko joera handitua legoke. Horretaz gain, emakumezkoek erraztasun handiagoa izango lukete kontsultetara laguntza eske joateko, sozialki onartuagoa baitago. Aldiz, gizonezkoetan, suminkortasunaren, portaera-asalduraren edo alkoholismoaren atzean ezkutatuko lirateke ondoez horiek $(8,9)$. Beraz, sintoma horiek interpretatzeko zailagoak izan daitezke medikuentzat, eta, hortaz, diagnostikatzeko zailagoak.Horrez gain, gizarteko "pentsamendu ideologiko" ezberdinek emakumezkoen "ahultasun psikologikoa" nabarmentzen dute, eta, horrek, arazo beraren aurrean pazientearen generoaren arabera medikuak balorazio ezberdina egitea eragin dezake (24). Are gehiago, historian zehar emakumezkoei esleitu zaizkien genero-rol tradizionalen ondorioz, emakumezkoetan agertzen diren zenbait gertaera, erditze osteko depresioa edota menopausia esaterako, tratatu beharreko arrazoi biologiko-naturaltzat hartzen dira eta ez testuinguru historiko-sozial determinatu baten parte. Ondorioz, antsietatea edota depresio-nahasmenduak emakumezkoetan gehiago diagnostikatzea gerta daiteke. Hau guztia kontuan izanik, gizonezkoak infradiagnostikatu eta emakumezkoak gainmedikatzen direla proposatzen da (8).

Laburbilduz, EAEn eta nazioartean aztertutako herrialdeetan emakumezkoen artean gizonezkoen artean baino antsiolitiko eta hipnotiko sedagarri gehiago kontsumitu direla esan dezakegu eta farmako kontsumituenak ere antzekoak direla. Interesgarria izango litzateke EAEko datuak pazienteen adinaren arabera edo beste zenbait faktoreren arabera (lanbidea, maila sozioekonomikoa, patologia) sailkatuta lortzea, modu horretara, faktore horiek kontsumoan duten eragina ikertu ahal izateko. Horrez gain, interesgarria litzateke EAEko datuak DDD bidez ikertzea eta, modu horretara, bilaketan baztertu diren ikerketekin konparatu ahal izatea. Are gehiago, interesgarria litzateke, baita ere, prebalentzia-kalkuluak egitea saldutako farmako kopuru osoa jakinda. Modu horretara, antsiolitiko eta hipnotiko sedagarrien erabileraren deskribapen osoa egitea lortuko genuke.

\section{Ondorioak}

1. Emakumezkoen antsiolitiko eta hipnotiko sedagarrien kontsumoa gizonezkoena baino handiagoa izan zen Europa, Amerika eta Asiako herrialde ezberdinetako ikerketetan. Diazepama eta lorazepama dira bentzodiazepina erabilienak.

2. EAEn saldu ziren antsiolitiko ontzien $\% 73$ eta hipnotiko sedagarrien $\% 66$ emakumezkoen artean eman ziren. Emakumezkoen artean kontsumitu zen ontzi kopurua 100 biztanleko, gizonezkoen artean baino 1,09 aldiz handiagoa izan zen antsiolitikoen kasuan eta 0,87 aldiz handiagoa hipnotiko sedagarrien kasuan.

3. EAEn emakumezkoek antsiolitikoak kontsumitzeko duten probabilitatea gizonezkoek dutena baino handiagoa da; 2,2 aldiz handiagoa antsiolitikoen kasuan eta 2 aldizhandiagoa hipnotiko sedagarrien kasuan.

4. EAEn ontzi salduenen artean lorazepam, lormetazepam eta alprazolam farmakoak daude.

5. Emakumezkoek gizonezkoek baino 2-4 aldiz probabilitate handiagoa dute klotiazepama, pinazolama edota diazepama kontsumitzeko, eta2 aldiz probabilitate handiagoa zolpidema, zopiklona edo zaleplona kontsumitzeko.

\section{Eskerrak}

Eusko Jaurlaritzako Osasun Saileko Farmaziako Zuzendaritzari, lan hau egiteko beharrezko datuak eskaintzeagatik.Lan honek "Accesit" saria jaso zuen genero-ikuspegia gradu-amaierako lanetan barne hartzearen Francisca De Aculodi Sarien VI. Edizioaren barruan. 


\section{Bibliografia}

1. Benedí J, Gómez del Río M. Ansiedad. Farmacia Profesional. 2007;21(1):50-55.

2. Tortella-Feliu M. Los trastornos de ansiedad en el DSM-5. Cuadernos de medicina psicosomática y psiquiatría de enlace. Rev iberoam Psicosom. 2014; 110:62-69.

3. Álamo C, Alonso ML, Cañellas F, Martín B, Perez H, Romero O, Terán J. Pautas de Actuación y seguimiento: insomnio [internet]. Madrid: Organización Médica Colegial (OMC); 2016 [kontsulta: 2018-12-20]. 82 or. Eskuragarri: https://www.ses.org.es/docs/guia-de-insomnio2016.pdf

4. Contreras A.Insomnio: generalidades y alternativas terapéuticas de última generación. Rev Med Clin Condes. 2013;24(3):433-441.

5. Ohayon MM, Sagales T. Prevalence of insomnia and sleep characteristics in the general population of Spain. Sleep Med. 2010;11(10):1010-1018.

6. Charney DS, Mihic SJ, Harris RA. Hipnóticos y sedantes. Hemen: Brunton L, Lazo J, Parker K, editors. Las bases farmacológicas de la terapéutica. México D.F: Mc-Graw-Hill Interamericana; 2006. p.401-427.

7. Rosman S, Le Vaillant M, Pelletier-Fleury N. Gaining insight into benzodiazepine prescribing in General Practice in France: a data-based study. BMC Family Practice. 2011;28(12):1-6.

8. Romo N, Vega A, Meneses C, Gil E, Markez I, Poo M. Sobre el malestar y la prescripción: un estudio sobre los usos de psicofármacos por las mujeres. Rev Esp de Drogodependencias. 2003;28(4):372-379

9. Carrasco-Garrido P, Hernández-Barrera V, Jiménez-Trujillo I, Esteban-Hernández J, ÁlvaroMeca A, López-de Andrés A, DelBarrio-Fernández JL, Jiménez-García R. Time trend in psychotropic medication use in Spain: a nationwide population-based study. IntJ of Environ Res Public Health. 2016;24;13(12):1177.

10. Codony $M$, Alonso J, Almansa J, Vilagut G, Domingo A, Pinto-Meza A, Fernández A, Serrano Blanco $A$, Márquez $M$, Haro JM. Uso de fármacos psicotrópicos en España. Resultados del estudio ESEMeD-España [Psychotropic medications use in Spain. Results of the ESEMeDSpain study]. Actas EspPsiquiatr. 2007;35 Suppl 2:29-36.

11. Simoni-Wastila L. Gender and Psychotropic Drug Use. Med Care. 1998; 36(1):88-94.

12. Eguía-Kareaga fundazioa. Avance de resultados de la encuesta sobre adicciones en la CAPV 2017 [internet]. EAE: eusko jaularitzako osasun saila; 2018 [Kontsulta: 2018-12-20]. 52 or. Eskuragarri:

https://www.euskadi.eus/contenidos/informacion/adicciones_euskadi_drogas/es_def/adjun tos/Euskadi-y-Drogas-2017.pdf

13. Instituto Nacional de Estadística. Población residente en la C.A. del País Vasco por fecha, sexo y edad. [Kontsulta: 2019-04-01][Internet]. PX-Web.2019. Eskuragarri: https://www.ine.es/jaxiT3/Datos.htm?t=31304

14. Kaspersen S, Pape K, Ose S, Gunnell D, Bjørngaard J. Unemployment and initiation of psychotropic medication: a case-crossover study of 2348552 Norwegian employees. OccupEnviron Med. 2016;73:719-726.

15. Hassan L, Senior J, Webb R, Frisher M, Tully M, While D, Shaw JJ. Prevalence and appropriateness of psychotropic medication prescribing in a nationally representative crosssectional survey of male and female prisoners in England. BMC Psychiatry. 2016;16(1):346.

16. Hall S, Chiu G, Kaufman D, Kelly J, Link C, Kupelian V, McKinlay JB. General exposures to prescription medications by race/ethnicity in a population-based sample: results from the Boston Area Community Health Survey. Pharmacoepidemiol Drug Saf. 2010;19:384-392. 
17. Quinn K, Baker M, Evans B. A population-wide profile of prescription drug use in Saskatchewan, 1989. CMAJ. 1992; 146(12):2177-2186.

18. Cunningham C, Hanley G, Morgan S. Patterns in the use of benzodiazepines in British Columbia: Examining the impact of increasing research and guideline cautions against longterm use. Health Policy. 2010;97(2-3):122-129.

19. Kokkevi A, Fotiou A, Arapaki A, Richardson C. Prevalence, Patterns, and Correlates of Tranquilizer and Sedative Use Among European Adolescents. J AdolescHealth. 2008;43(6):584-592.

20. Alvarenga JM, Loyola Filho Al, Firmo JO, Lima-Costa MF, Uchoa E. Prevalence and sociodemographic characteristics associated with benzodiazepines use among community dwelling older adults: the Bambuí Health and Aging Study (BHAS). Braz J Psychiatry. 2007;30(1):7-11.

21. Nomura K, Nakao M, Sato M, Yano E. Regular prescriptions for benzodiazepines: acrosssectional study of outpatients at a university hospital. Intern Med. 2006;45(22):1279-1283.

22. Petit N, Delporte J, Ansseau M, Albert A, Jeusette F. Drug utilization review of oral forms of benzodiazepines in a Belgian 635-bed teaching hospital. Pharm World Sci. 1994;16(4):181186.

23. Van der Waals F, Mohrs J, Foets M. Sex differences among recipients of benzodiazepines in Dutch general practice. BMJ. 1993;307:363-366.

24. Gil García E, Romo Avilés N, Poo Ruiz M, Meneses Falcón C, Markez Alonso I, Vega Fuente A. Género y psicofármacos: la opinión de los prescriptores a través de una investigación cualitativa. Aten Primaria. 2005;35(8):402-407. 